\title{
Alteration in the Metabolism of Dihydrotestosterone in Elderly Men with Prostate Hyperplasia
}

\author{
I. Morimoto, A. Edmiston, and R. Horton with technical assistance of D. Hawks, \\ Section of Endocrinology, Department of Medicine, Los Angeles County- \\ University of Southern California School of Medicine, \\ Los Angeles, California 90033
}

A B S T R A C T In vivo androgen kinetics were determined in six young (21-49 yr) and elderly men $(62-77$ yr) with prostate hyperplasia (BPH). Steadystate infusions of $\left[{ }^{14} \mathrm{C}\right]$ testosterone and $\left[{ }^{3} \mathrm{H}\right]$ androstanediol ( $3 \alpha$ diol) were given, which allowed determination of the conversions testosterone $\rightarrow$ dihydrotesterone (DHT) $\leftrightarrows 3 \alpha$ diol. These infusions also yield metabolic clearance data which, together with measurement of nonisotopic steroid levels, yield estimations of blood production rates. The production rate for testosterone was $6.04 \pm 1.66$ vs. $3.69 \pm 0.62 \mathrm{mg} / \mathrm{d}$, whereas the production rate for $3 \alpha \mathrm{diol}$ was $319 \pm 57$ and $193 \pm 34 \mu \mathrm{g} / \mathrm{d}$ ( $P<0.05$ both groups). The irreversible conversion rate of testosterone to DHT was $3.1 \pm 0.4$ and $3.5 \pm 0.9 \%$ (NS). The back conversion of $3 \alpha \mathrm{diol}$ to DHT was high $(68 \pm 25$ vs. $81 \pm 17, \mathrm{NS})$ indicating that $3 \alpha$ diol might cause BPH as a result of conversion to DHT in vivo. The conversion of DHT to $3 \alpha \mathrm{diol}$ is reduced in the elderly group (15.8 \pm 2.6 and $6.3 \pm 1.4$, $P<0.001)$. Since DHT formation in the prostate is a key event in development of BPH and blood DHT appears to be a measure of extrasplanchnic sexual target tissue activity, our in vivo studies suggest that the tissue increase in DHT may result from reduced metabolism and the activity of $3 \alpha$-oxidoreduction favors the oxidative pathway in elderly men.

\section{INTRODUCTION}

Dihydrotestosterone (DHT) $)^{1}$ plays a central role in the formation of the prostate during fetal life and in the development of both human and canine prostate hyperplasia (BPH) in late adult life (1-3). DHT levels are increased in $\mathrm{BPH}$ tissue, particularly in the peri-

Received for publication 12 May 1980 and in revised form 9 June 1980.

${ }^{1}$ Abbreviations used in this paper: $\mathrm{BPH}$, prostate hyperplasia; 3 $\alpha$ diol, androstanediol; DHT, dihydrotestosterone; MCR, metabolic clearance rate; PR, production rate. urethral area (4). DHT is a potent growth factor (5), and given in an appropriate dose induces $\mathrm{BPH}$ in young dogs $(6,7)$. Another testosterone conversion product, androstanediol (3 $3 \alpha \mathrm{diol})$, can induce canine BPH (8), however, it is not bound to target tissue receptors (9) and studies in vitro suggest that it is efficiently converted back to DHT (10).

In man, secreted testosterone is peripherally converted into DHT and $3 \alpha$ diol by nongonadal tissues and a majority of both androgens in blood are derived from secreted testosterone $(11,12)$. The importance of these observations was increased when it became clear that DHT conversion did not occur in muscle (13), and we have demonstrated that both DHT and $3 \alpha$ diol are derived from conversion in extrasplanchnic tissue (14). This work indicates that DHT and 3adiol production measured in the circulation may be a reflection of events occurring in sexual target tissue.

We report in vivo kinetic data that is suggestive of an alteration in androgen interconversion in the aging male.

\section{METHODS}

Subjects. The studies were performed on six young men ages 21-49 yr and in a similar number of healthy elderly men ages $62-77$ yr who had asymptomatic but palpable BPH and volunteered for the study.

Radioactive steroids. $\left[4-{ }^{14} \mathrm{C}\right]$ testosterone $(58 \mathrm{mCi} / \mathrm{mM}$ sp act), $\left[1,2-{ }^{3} \mathrm{H}\right]$ testosterone, and $\left[1,2-{ }^{3} \mathrm{H}\right] 3 \alpha \mathrm{diol}(40 \mathrm{Ci} / \mathrm{mM}$ sp act) were obtained from New England Nuclear (Boston, Mass.) and then radiochemically purified by paper chromatography (12)

Assay of plasma androgens. The concentration of sex steroids were measured by immunoassay methods described from our laboratory (15-17). Samples were taken before the infusion every $20 \mathrm{~min}$ (three times) to minimize short-term episodic fluctuation in concentrations.

Kinetic study of metabolic clearance and conversion ratios. $\left[{ }^{14} \mathrm{C}\right]$ testosterone and $\left[{ }^{3} \mathrm{H}\right] 3 \alpha$ diol were given by constant infusion over a 2 -h period as described $(11,12)$. The infusion solution included $20-25 \mu \mathrm{Ci}\left[{ }^{14} \mathrm{C}\right]$ testosterone and $3-5 \mu \mathrm{Ci}$ $\left[{ }^{3} \mathrm{H}\right] 3 \alpha$ diol in $55 \mathrm{ml}$ of $8 \%$ ethanol in saline. A primary dose of $8 \mathrm{ml}$ was given at the beginning of the infusion at $9 \mathrm{a} . \mathrm{m}$. and the infusion continued for $2 \mathrm{~h}$. Previous reports by us have 
indicated that steady-state conditions are obtained by $90 \mathrm{~min}$ (12).

Analysis of precursor and product radioactivity. 25-ml samples of plasma obtained at 105 and $120 \mathrm{~min}$ were mixed with 6,000-dpm [ ${ }^{3} \mathrm{H}$ ]testosterone, $2 \mu \mathrm{g}$ DHT, and $2 \mu \mathrm{g} 3 \alpha$ diol for correction of losses and the plasma extracted with solvent as described (14). The dried extracts were then chromatographed on a celite column (18), collecting testosterone, DHT, and $3 \alpha$ diol fractions. The Bush A system (petroleum ether/ methanol/water, 5:4:1) was used for final purification of the testosterone and $3 \alpha \mathrm{diol}$ and the Bush $\mathrm{B}_{3}$ system (Skellysolve C (Skelly Oil Co., Tulsa, Okla.) methanol/benzene/water 3.5:1.5:4:1) for DHT. The conversion of testosterone to DHT was calculated from ${ }^{14} \mathrm{C}$ counts and the other conversions were determined from ${ }^{3} \mathrm{H}$ counts. An aliquot of samples after final purification was measured by radioimmunoassay for recovery correction. Testosterone purification losses were corrected for by $\left[{ }^{3} \mathrm{H}\right]-$ testosterone. Samples were counted for 150 or $200 \mathrm{~min}$ (3-4 $\times 50 \mathrm{~min}$ ) and counting errors were $<5 \%$ in all cases. For the critical determination of DHT to $3 \alpha$ diol conversions, counting rates were similar in both young and elderly groups due to reduction in metabolic clearance in the latter. In elderly patient R.R., $\left[{ }^{14} \mathrm{C}\right] \mathrm{DHT}$ was infused, yielding a much higher count rate, however, conversion values were not different from those obtained using $\left[{ }^{14} \mathrm{C}\right]$ testosterone. In the remaining studies of DHT conversion, counting rates ranged from 2 to 25 times background. We have previously shown that count rates handled in this manner, yield errors that are $<5 \%$ (19).

The testosterone and $3 \alpha$ diol metabolic clearance rates can be calculated from the ratio of counts infused per unit time and counts of the purified steroid per volume of plasma corrected for purification losses. The conversion ratios (testosterone-DHT, DHT-3 $\alpha$ diol, and $3 \alpha$ diol-DHT) were determined as described $(11,12)$ as the ratio of counts in plasma as product and precursor steroid.

Proof of purity of labeled precursor and products in the circulation. Radiochemical purity was ascertained by con- stancy of the carbon-tritium ratio of compounds after acetylation and an additional chromatography step as described $(11,12)$.

\section{RESULTS}

Plasma concentration of nonisotopic steroids. The concentration of nonradioactive testosterone and $3 \alpha$ diol in young men was $584 \pm 123$ and $18 \pm 2$ (SD) ng/dl, respectively (Table I). Values were $537 \pm 113$ and $15 \pm 4$ (SD) $\mathrm{ng} / \mathrm{dl}$ in the elderly group. No significant difference in plasma concentration was noted in the two groups.

Metabolic clearance (MCR) and production rates $(P R)$. The MCR for testosterone was $1,033 \pm 210$ in young vs. $658 \pm 174$ liters/d in the elderly group $(P<0.02)$. The MCR for $3 \alpha$ diol was $1,798 \pm 425$ vs. $1,370 \pm 207$ liters/d $(P<0.05)$. When the multiple morning plasma concentration and MCR were considered, the PR for testosterone was $6.04 \pm 1.66 \mathrm{vs}$. $3.69 \pm 0.62 \mathrm{mg} / \mathrm{d}$, whereas the PR for $3 \alpha \mathrm{diol}$ was $319 \pm 57$ and $193 \pm 34 \mu \mathrm{g} / \mathrm{d}$, respectively. In both cases, the values between young and elderly men were different $(P<0.05)$ (Fig. 1$)$.

Conversion rates in the circulation. Conversion ratios for both groups are shown in Table I and Fig. 2. The irreversible conversion ratio of testosterone to DHT was $3.1 \pm 0.4$ and $3.5 \pm 0.9 \%$ (NS). The back conversion of $3 \alpha$ diol to DHT is high in both groups $(68 \pm 25$ vs. $81 \pm 17 \%)$. No significant difference in formation of DHT from testosterone and $3 \alpha$ diol was

TABLE I

Age, Plasma Testosterone and 3 adiol, together with MCR, PR, and Conversion Ratios Measured during Steady-state Infusions of $\left[{ }^{14} \mathrm{C}\right]$ Testosterone and $\left[{ }^{3} \mathrm{H}\right] 3$ odiol in Young and Elderly Men

\begin{tabular}{|c|c|c|c|c|c|c|c|c|c|c|}
\hline \multirow[b]{3}{*}{ Subjects } & \multirow[b]{3}{*}{ Age } & \multirow{2}{*}{\multicolumn{2}{|c|}{ Plasma }} & \multirow{2}{*}{\multicolumn{2}{|c|}{ MCR }} & \multirow{2}{*}{\multicolumn{2}{|c|}{ PR }} & \multicolumn{3}{|c|}{ Conversion rate } \\
\hline & & & & & & & & Testosterone- & & \\
\hline & & Testosterone & 3adiol & Testosterone & $3 \alpha$-diol & Testosterone & 3adiol & DHT & DHT-3adiol & 3adiol-DHT \\
\hline & $y r$ & \multicolumn{2}{|c|}{$n g / d l$} & \multicolumn{2}{|c|}{ liters/d } & $m g / d$ & $\mu g / d$ & & $\%$ & \\
\hline R.A & 21 & 526 & 16 & 1,344 & 2,320 & 7.07 & 371 & 3.4 & 15.9 & 52.0 \\
\hline K.O & 33 & 661 & 18 & 1,168 & 1,719 & 7.72 & 309 & 3.0 & 16.7 & 90.6 \\
\hline H.W & 45 & 498 & 18 & 1,099 & 2,232 & 5.44 & 401 & 2.8 & 8.7 & 85.3 \\
\hline J.J & 48 & 468 & 21 & 817 & 1,211 & 3.82 & 254 & 2.7 & 18.0 & 26.7 \\
\hline J.P & 48 & 795 & 18 & 958 & 1,497 & 7.62 & 269 & 3.0 & 18.2 & 85.0 \\
\hline J.C & 49 & 562 & 16 & 814 & 1,810 & 4.57 & 312 & 3.9 & 17.4 & 66.4 \\
\hline Mean \pm SD & & $584 \pm 123$ & $18 \pm 2$ & $1,033 \pm 210$ & $1,798 \pm 425$ & $6.09 \pm 1.65$ & $319 \pm 57$ & $3.1 \pm 0.4$ & $15.8 \pm 3.6$ & $67.7 \pm 24.7$ \\
\hline K.J & 62 & 386 & 12 & 484 & 1,465 & 3.10 & 175 & 2.8 & 5.2 & 90.7 \\
\hline R.R & 64 & 595 & 18 & - & 1,337 & - & 241 & - & 5.4 & 55.4 \\
\hline B.L & 66 & 710 & 21 & 591 & 1,081 & 4.19 & 227 & 2.6 & 8.7 & 62.3 \\
\hline J.W & 67 & 565 & 14 & 672 & 1,186 & 3.80 & 166 & 4.7 & 6.1 & 94.7 \\
\hline C.M & 74 & 462 & 10 & 946 & 1,559 & 4.37 & 156 & 3.3 & 7.2 & 84.7 \\
\hline J.W & 77 & 501 & 12 & 599 & 1,594 & 3.00 & 191 & 4.7 & 5.4 & 95.9 \\
\hline Mean $\pm S D$ & & $537 \pm 113$ & $15 \pm 4$ & $658 \pm 174$ & $1,370 \pm 207$ & $3.69 \pm 0.62$ & $193 \pm 34$ & $3.5 \pm 0.9$ & $6.3 \pm 1.4$ & $80.6 \pm 17.4$ \\
\hline$P$ value & & NS & NS & $<0.02$ & $<0.05$ & $<0.05$ & $<0.01$ & NS & $<0.001$ & NS \\
\hline
\end{tabular}




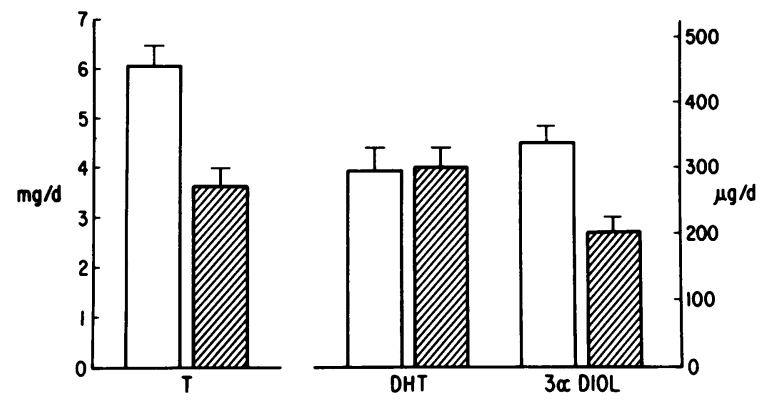

Figure 1 Blood PR of testosterone (T), DHT, and 3adiol in young and elderly men with BPH. Production rates were calculated as the product of the metabolic clearance and morning blood levels. The DHT production was determined in another study (19) and is included for comparison.

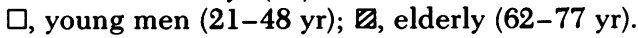

noted. However, the conversion rate of DHT to $3 \alpha$ diol is greatly reduced in the elderly group when compared with the young group (15.8 \pm 2.6 and $6.3 \pm 1.4 \%, P<0.001$ ).

\section{DISCUSSION}

The MCR of all three androgens are reduced in elderly men. In previous studies we reported this for testosterone and DHT (20). We now confirm this and document a reduction in MCR for $3 \alpha$ diol in elderly men. Reduced MCR of sex steroids in elderly men is probably the result of increased sex hormone-binding globulin levels (21) as well as reduced cardiac output and splanchnic blood flow in the older man. A significant reduction in the production rate of both testosterone and $3 \alpha$ diol is observed in the elderly male as a result

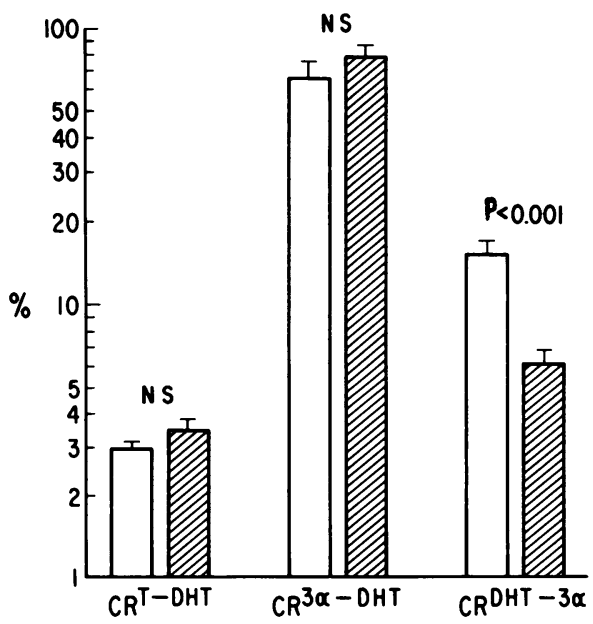

Figure 2 Conversion rates (CR) of testosterone to DHT

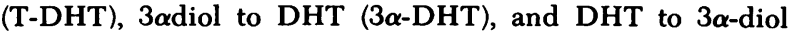
$(\mathrm{DHT}-3 \alpha)$ determined in the general circulation under steady-state conditions during infusion of $\left[{ }^{14} \mathrm{C}\right]$ testosterone and $\left[{ }^{3} \mathrm{H}\right] 3 \alpha$ diol. $\square$, young men (21-48 yr); $\square$, elderly of reduced clearance. This reduction is in contrast to the increased plasma DHT (16) and the production rate of DHT, which is not reduced (20).

Sexual tissue is capable of metabolizing testosterone to active hormonal products. Wilson and collaborators (4) studied this conversion in vitro and concluded that it was not increased in BPH tissue when coenzyme (NADPH) was not added to the medium. Our kinetic studies describe the overall events of blood production. Nevertheless, we suggest that these androgen interconversions may be an accurate reflection of what is occurring in prostate and other sexual tissue since muscle, the anabolic target for testosterone, lacks $5 \alpha$-reductase and the splanchnic tissue is not the source of DHT. The conversion rate of testosterone to DHT measured in blood is not increased, in agreement with the tissue studies noted above. The in vivo PR of DHT is maintained, whereas that of $3 \alpha$ diol is reduced. In BPH tissue DHT levels are increased, whereas $3 \alpha$ diol levels are reduced (22).

Our analysis of the conversion of $3 \alpha$ diol back to DHT is also in agreement with in vitro studies of prostate tissue (10). Most of the $3 \alpha$ diol in vivo and in vitro is converted back to DHT. This efficient back conversion explains why $3 \alpha$ diol is an effective androgen and can induce BPH in the canine model.

A major difference in the metabolism of DHT to $3 \alpha$ diol was observed in vivo in elderly men with $\mathrm{BPH}$. This conversion is significantly reduced in elderly men with BPH. When the transfer constant is calculated as the ratio between rate of appearance of product and infusion of precursor using the appropriate MCR (11), the [ $\rho$ ] for DHT to $3 \alpha$ diol is 40 and $20 \%$, respectively. These in vivo kinetics suggest that the accumulation of DHT in sexual tissue is not the result of increased production, but reduced metabolism. This observation is in keeping with the in vitro observations that DHT levels are increased in prostate and seminal vesicles, that $3 \alpha$-oxidoreductase activity in prostate is increased (23), however, tissue levels of $3 \alpha$ diol are reduced (22). We suggest from our blood kinetic studies that BPH is the result of a change in the state of this key enzyme whereby the oxidation pathway is favored over reduction, resulting in accumulation of DHT, a potent growth stimulus to the prostate. Intervention would logically include either altering $5 \alpha$-reductase activity or enhancing the reductive activity of $3 \alpha$-oxidoreductase.

\section{ACKNOWLEDGMENTS}

This work was supported by National Institutes of Health grants AM 13710 and T32 AM 07119.

\section{REFERENCES}

1. Imperato-McGinley, J., L. Guerrero, T. Gautier, and R. E. Peterson. 1974. Steroid $5 \alpha$-reductase deficiency in men: 
an inherited form of male pseudohermaphroditism. Science (Wash. D. C.). 186: 1213-1215.

2. Bruchovsky, N., and J. D. Wilson. 1968. The conversion of testosterone to $5 \alpha$-androstane-17 $\beta-01-3$ one by rat prostate in vivo and in vitro. J. Biol. Chem. 243: 2012-2021.

3. Bruchovsky, N., and J. D. Wilson. 1968. The intranuclear binding of testosterone and $5 \alpha$-androstan-17 $\beta$-01-3one by rat prostate. J. Biol. Chem. 243: 5953-5960.

4. Siiteri, P. K., and J. D. Wilson. 1970. Dihydrotestosterone in prostatic hypertrophy. I. The formation and content of dihydrotestosterone in the hypertrophic prostate of man. J. Clin. Invest. 49: 1737-1745.

5. Baulieu, E. E., I. Lasnitzki, and R. Robel. 1968. Metabolism of testosterone and action of metabolites on prostate glands grown in organ culture. Nature (Lond.). 219: 1155-1156.

6. Moore, R. J., J. M. Gazak, J. F. Quebbeman, and J. D. Wilson. 1979. Concentration of dihydrotestosterone and $3 \alpha$-androstanediol in naturally occurring and androgen induced prostatic hyperplasia in the dog. J. Clin. Invest. 64: 1003-1010.

7. Deklerk, D. P., D. S. Coffey, L. L. Ewing, I. R. McDermott, W. G. Reiner, C. H. Robinson, W. W. Scott, J. D. Strandberg, P. Talaley, P. C. Walsh, L. G. Wheaton, and B. R. Zinkim. 1979. Comparison of spontaneous and experimental induced canine prostatic hyperplasia. $J$. Clin. Invest. 64: 842-849.

8. Walsh, P. C., and J. D. Wilson. 1976. The induction of prostatic hypertrophy in the dog with androstanediol. J. Clin. Invest. 57: 1093-1097.

9. Moore, R. J., J. M. Gazak, and J. D. Wilson. 1979. Regulation of cytoplasmic dihydrotestosterone binding in the dog prostate by $17 \beta$-estradiol. J. Clin. Invest. 63: 351-357.

10. Bruchovsky, N. 1971. Comparison of the metabolites formed in the rat prostate following the in vivo administration of seven natural androgens. Endocrinology. 89: $1212-1222$.

11. Ito, T., and R. Horton. 1971. The source of plasma dihydrotestosterone in man. J. Clin. Invest. 50: 16211627.

12. Kinouchi, T., and R. Horton. 1974. $3 \alpha$-androstanediol kinetics in man. J. Clin. Invest. 54: 646-652.
13. Gloyna, R. E., and J. D. Wilson. 1969. A comparative study of the conversion of testosterone to $17 \beta$-hydroxy-5 $\alpha$ androstane-3one (DHT) by prostate and epididymis. J. Clin. Endocrinol. Metab. 29: 970-977.

14. Ishimaru, T., W. A. Edmiston, L. Pages, and R. Horton. 1978. Splanchnic extraction and conversion of testosterone and dihydrotestosterone in man. J. Clin. Endocrinol. Metab. 46: 528-533.

15. Kinouchi, T., L. Pages, and R. Horton. 1973. A specific radioimmunoassay for testosterone in peripheral plasma. J. Lab. Clin. Med. 82: 309-316.

16. Horton, R., P. Hsieh, J. Barberia, L. Pages, and M. Cosgrove. 1975. Altered blood androgens in elderly men with prostate hyperplasia. J. Clin. Endocrinol. Metab. 41: 793-796.

17. Barberia, J., L. Pages, and R. Horton. 1976. Measurement of androstanediol in plasma in a radioimmunoassay using celite column chromatography. Fertil. Steril. 27: 11011104.

18. Barberia, J. M., and I. H. Thorneycroft. 1974. Simultaneous measurement of testosterone and dihydrotestosterone. Steroids. 23: 757-766.

19. Horton, R., and J. F. Tait. 1967. The in vivo conversion of dehydroisoandrosterone to plasma androstanedione and testosterone in man. J. Clin. Endocrinol. Metab. 27: 79-88.

20. Ishimaru, T., L. Pages, and R. Horton. 1977. Altered metabolism of androgens in elderly men with benign prostatic hyperplasia. J. Clin. Endocrinol. Metab. 45: 695-701.

21. Pirke, K. M., and P. Doerr. 1973. Age-related changes and inter-relationships between plasma testosterone, estradiol and testosterone-binding globulin in normal adult males. Acta Endocrinol. 74: 792-800.

22. Geller, J., J. Albert, D. Lopez, S. Geller, and G. Niwayama. 1976. Comparison of androgen metabolites in benign prostatic hypertrophy (BPH) and normal prostate. J. Clin. Endocrinol. Metab. 43: 686-688.

23. Jacobi, G. H., and J. D. Wilson. 1977. Formation of $5 \alpha$ androstane-3 $\alpha, 17 \beta$-diol by normal and hypertrophic human prostate. Endocrinology. 44: 107-115. 